\title{
Effect of Cold Rolling on Metal Hydrides
}

\author{
Jacques Huot* and Manuel Tousignant \\ Université du Québec à Trois-Rivières, 3351 des Forges, Trois-Rivières, QC, G9A 5H7, Canada
}

In this paper we review the recent studies of the effect of cold rolling on selected metal hydride systems. Magnesium is the most studied element in this perspective either as pure element, alloys, allied with iron or in a composite with $\mathrm{AB}_{5}$ alloy alloys. Other systems will also be discussed such as titanium, $\mathrm{AB}_{5}$ and $\mathrm{AB}_{2}$ systems. After a critical review of these systems, we will discuss in detail the effect of cold rolling on $\mathrm{Mg}_{2} \mathrm{Ni}$ alloy and shows that cold rolling is efficient to improve the first hydrogenation but has basically no impact of subsequent hydrogenation kinetics. [doi:10.2320/matertrans.MF201939]

(Received April 9, 2019; Accepted June 5, 2019; Published July 25, 2019)

Keywords: cold rolling, metal hydrides, hydrogen storage

\section{Introduction}

In this paper we will review how cold rolling could enhance the hydrogen storage properties, particularly the kinetics, of metal hydrides. But first we should discuss about the terminology. The term Cold Rolling (CR) used here could also be called Accumulative Roll Bonding (ARB) technique. Sometimes the term ARB is reserved to the case where, prior to stacking, the metal sheets surfaces are cleaned and polished in order to get better sticking between them. In this paper, CR will be used to describe also ARB. We should also stress the difference between $\mathrm{CR}$ and the other main Severe Plastic Deformation techniques such as Equal Chanel Angular Pressing (ECAP) and High Pressure Torsion (HPT). In ECAP and HPT the sample doesn't experience an important variation of dimensions while, for CR, the dimensions change. In fact, $\mathrm{CR}$ may not be considered a 'true' SPD technique. This is even more problematic for metal hydrides because, in their hydride states, many metal hydrides are brittle and will not experience a plastic deformation upon rolling but mainly a particle size reduction, introduction of defects, etc. However, these outcomes may help the hydrogenation/dehydrogenation behaviours of the processed alloys or hydrides. Therefore, study of cold rolled metal hydrides is interesting from a fundamental as well as a practical point of view.

In this paper, after a brief overview of the technique, we will critically discuss recent results of hydrogen storage properties of cold rolled metal hydrides.

\section{Experimental Procedure}

Cold rolling is a well-known metalworking technique where a metal stock is inserted between two rotating rolls which, by turning, reduce the piece's thickness. The term cold rolling is used when the temperature of the metal is below its recrystallization temperature. When the temperature is higher than the recrystallization temperature, the term hot rolling is used. The vast majority of the rollings performed on metal hydrides are under the recrystallization temperature. An important difference of cold rolling compared to other SPD techniques is that, in cold rolling, the grain boundaries

*Corresponding author, E-mail: jacques.huot@uqtr.ca

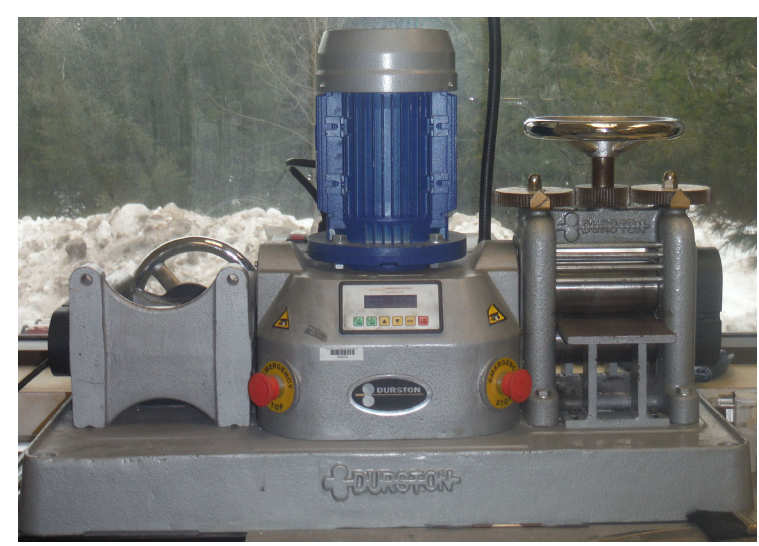

Fig. 1 Modified cold rolling apparatus for horizontal (right) and vertical (left) rolling.

are mainly low angle misorientation while the other SPD techniques produce high angle misorientation. ${ }^{1)}$

As usually metal hydrides are in a powder form, processing it in a cold rolling apparatus conventional configuration is problematic. This problem could be solved easily by rotating the set of rolls $90^{\circ}$ to make rolling vertical instead of horizontal. This new configuration makes the rolling of powder much easier.

Usually, CR is performed on sheets or foils of metals. However, metal hydrides usually come in powder form. A simple way to process powder by cold rolling is to simply turn the rolling machine $90^{\circ}$ (see Fig. 1). This way, powder materials could be easily rolled. A more complete description of the technique could be found in Ref. 2).

In the case of the $\mathrm{Mg}_{2} \mathrm{Ni}$ system reported in this paper, the as-received $\mathrm{Mg}_{2} \mathrm{Ni}$ powder was provided by Hydro-Quebec Research Center. The cold-rolling apparatus used was a Durston DRM 130 modified for vertical rolling. To prevent contamination from the rolls, the rolling was performed by inserting the powder between two stainless steels 316 plates. Rolling had for effect of braking the particles and consolidating the powder into a flat sheet that fell down vertically into a collection pan. The sheet/powder was collected and rolled again up to the final number of rolling. All rollings were performed in air at room temperature. Crystal structure was analyzed from X-ray powder diffraction patterns registered on a Bruker D8 Focus apparatus with $\mathrm{CuK} \alpha$ radiation. Phases abundances as well as crystallite size, 
lattice parameters and microstrain were evaluated from Rietveld refinement method using Topas software via the fundamental parameters approach. ${ }^{3,4)}$ The hydrogen kinetic curves were measured with a Sieverts-type apparatus. First hydrogenation kinetics were performed at $623 \mathrm{~K}$ under a hydrogen pressure of $2000 \mathrm{kPa}$.

\section{Results and Discussion}

In this section we will review the recent investigations of the effect of cold rolling on various metal hydride systems. A discussion of the earlier research is given in Ref. 2).

\subsection{Magnesium and magnesium-based alloys}

Magnesium is attractive for hydrogen storage because of his high hydrogen capacity (7.6wt.\%) and low cost. However, the temperature of operation is too high for most practical applications. Another problem is that the first hydrogenation is usually difficult and lengthy thus increasing the production cost. Cold rolling magnesium will produce intense strain-hardening and introduce defects and dislocations. These could then act as nucleation points for hydrogen and facilitate hydrogenation. Many studies have been performed on cold rolling magnesium. Here, only the most recent investigations will be covered. A more complete review of the literature could be found in Ref. 2).

Because of the strong strain hardening of magnesium, many investigations are made instead on magnesium hydride. Recently, El-Eskandarany et al. discovered that a combination of ball-milling, cold rolling and ball milling under hydrogen produced a new metastable phase of fcc- $\mathrm{MgH} 2$ (space group $\mathrm{Fm} 3 m(225)$ ) with a lattice parameter of $0.4436 \mathrm{~nm} .^{5)}$ This result open-up the possibility of using combination of severe plastic deformation techniques to obtain new metastable phases. Grill et al. have cold rolled $\mathrm{MgH}_{2} 5$ times in air at room temperature between stainless steel plates. ${ }^{6)}$ They found a fast hydrogenation/dehydrogenation kinetics and initial hydrogen capacity of $6 \mathrm{wt} . \%$ but the capacity decreased with cyclin, reaching a value of only 4 wt. $\%$ after 100 hydrogenation/dehydrogenation cycles. Kinetics were also getting slower with cycling. They attributed this loss of capacity and kinetics to a limited diffusion of hydrogen within the hydride phase, and a gradual annealing of induced lattice defects with cycling. Therefore, cycling reduced the number of nucleation sites for both hydride(hydrogenation) and $\mathrm{Mg}$ phase formation (dehydrogenation). Márquez et al. have cold rolled $\mathrm{MgH}_{2}$ under protective atmosphere. ${ }^{7}$ ) They found that the hydrogen storage capacities and absorption kinetics improved with the number of rolling passes and roll rotation frequency. They attributed the improvements to the smaller crystallite and particle sizes, as well as a change in the morphology of the starting $\mathrm{MgH} 2$ powder. Also, because of the inert atmosphere there was no creation of deleterious oxides and hydroxides. However, improvement of desorption kinetics was mainly due to reduction of particle size. They also showed that reduction of crystallite size could be achieved much faster by cold rolling than by ball milling.

The effect of cold rolling on the hydrogen storage properties of commercial magnesium alloys have also been intensively studied. Soyama et al. studied the effect of cold rolling the commercial magnesium alloy ZK60 of composition, in wt.\%, of $\mathrm{Mg} 91.5 \%, \mathrm{Zn} \mathrm{5 \% ,Zr} \mathrm{1 \% ,} \mathrm{Mm} \mathrm{2.5 \%} \mathrm{where}$ $\mathrm{Mm}$ is a mischmetal of composition Ce $55 \%$, La $24 \%, \mathrm{Nd}$ $15 \%$ and $\operatorname{Pr} 4 \%{ }^{8}$ ) The alloy was first subjected to ECAP or melt spinning (MS) and thereafter cold rolled in air at room temperature. The ECAP and MS samples consisted of a main $\alpha$-Mg phase with a small proportion intermetallic phases that were tentatively associated to $\mathrm{Mg}-\mathrm{Zn}$ and $\mathrm{Mg}-\mathrm{Zn}-$ Rare earth type. Despite the fact that ECAP and MS alloys had different microstructures, the effect of cold rolling was to induce a strong (002) texture and breakage of the intermetallic phases. Texturing was more important for the ECAP sample. It was found that cold rolling enhanced the hydrogenation kinetics as well as the total capacity for both ECAP and MS prepared alloys. The authors explained this by the presence of (002) texture which provide an easier direction for hydrogen diffusion. They also mentioned the catalytic effect of the secondary phase is enhanced by cold rolling because these phases could act as nucleation points for the hydride phase.

Low temperature rolling of AZ91 magnesium alloy of composition in wt.\% of $\mathrm{Mg} 90 \%, \mathrm{Al} 9 \%$ and $\mathrm{Zn} 1 \%$ was investigated by Floriano et al. ${ }^{9)}$ For the low temperature rolling, the sample was immersed in liquid nitrogen for 5 minutes before performing the rolling. It was found that rolling at low temperature increased the hydrogenation kinetics and capacity of the samples compared to room temperature rolling. Besides the usual (002), this enhancement was explained by the presence of microcracks and high number of exposed interfaces in the low temperature rolled sample. It was also found that, as the rolling was performed in air, the surface is contaminated by oxides $\mathrm{MgO}$, hydroxide $\mathrm{Mg}(\mathrm{OH})_{2}$ and $\mathrm{MgCO}_{3}$. Thus, surface contamination plays an important role in the first hydrogenation process. This was confirmed by the faster first hydrogenation when the surface of the cold rolled sample was polished. Another factor that made the low temperature rolling more effective was the generation of a larger number of cracks, resulting in larger surface area compared to the room temperature rolling.

\subsection{Magnesium iron system}

Among metal hydrides, the intermetallic $\mathrm{Mg}_{2} \mathrm{Fe}$ has the highest hydrogen volumetric density $\left(150 \mathrm{~kg} \mathrm{H}_{2} / \mathrm{m}^{3}\right)$. However, as magnesium and iron are totally immiscible, the formation of the ternary hydride is impaired by the slow interdiffusion of $\mathrm{Mg}$ and $\mathrm{Fe}$. Therefore, having a fine distribution of $\mathrm{Fe}$ in $\mathrm{Mg}$ could help the hydrogenation kinetic and the completeness of the reaction. Jun et al. mixed magnesium and iron powder with $0.5 \mathrm{wt} . \%$ of oleylamine as a binding agent and cold rolled the mixture in air for up to 50 passes in steps of 10 passes. $^{10)}$ They found that increasing number of rolling passes lead to finer layers of Fe, reaching a thickness of $10 \mathrm{~nm}$ for iron after 50 rolling passes. The rate of formation of $\mathrm{Mg}_{2} \mathrm{FeH}_{6}$ formation increased with decreasing thickness of Fe layers. However, large number of rolling passes favorized the formation of $\mathrm{MgO}$ and reduced the total capacity reached.

The $2 \mathrm{Mg}+\mathrm{Fe}$ system was also studied by de Lima et al. who used carbon nanotubes (CNT) as a catalyst. ${ }^{11)}$ They investigated three processing routes: hot extrusion, cold- 
rolling and extrusion followed by cold-rolling. They found that the optimum amount of CNT for hydrogenation/ dehydrogenation was $5 \mathrm{wt} \%$ and the CNT were not destroyed by the mechanical processing. Single CR was found to be the best route, the composite $2 \mathrm{MgFe} / 5 \mathrm{wt} . \%$ CNTs achieving $73 \%$ of the theoretical capacity of $\mathrm{Mg}_{2} \mathrm{FeH}_{6}$.

The system $\mathrm{Mg}+8 \mathrm{~mol} \% \mathrm{Fe}$ was studied by Antiqueira et al. using different morphologies of iron: wires, pieces of iron wool or unwound iron wool. ${ }^{12)}$ As expected, rolling induced a (002) texture for all samples. The hydrogenation kinetics and reversible capacity were improved with addition of iron. This was explained by grain size reduction, increased density of cracks and redistribution of Fe for the cold rolled samples.

\subsection{Magnesium- $\mathbf{A B}_{5}$ system}

One of the drawbacks of magnesium hydride is its high temperature of operation. One way to improve the hydrogenation/dehydrogenation kinetics is to mix magnesium with a $\mathrm{AB}_{5}$ low temperature hydride. ${ }^{13,14)}$ Recently, Márquez et al. used cold rolling under an inert atmosphere to mix $\mathrm{Mg}$ and $\mathrm{LaNi}_{5}$ powders to form composites. ${ }^{15)}$ The composites showed a nanocrystalline structure after cold rolling and the hydride phases $\mathrm{MgH}_{2}, \mathrm{Mg}_{2} \mathrm{NiH}_{4}$ and $\mathrm{LaH}_{3}$ were seen after cycling. The authors explained the fast kinetics by the formation of intermediate hydrides $\mathrm{LaH}_{3}$ and $\mathrm{Mg}_{2} \mathrm{NiH}_{4}$.

\subsection{Titanium system}

Titanium hydride is too stable to be considered for hydrogen storage. However, it could be used for production of powders by first hydrogenating Ti sponge, ingot, or mill products, crushing and/or grinding it to the desired powder size, and then dehydrogenating the material to produce what is known as hydride-dehydride (HDH) Ti powder. ${ }^{16)}$ Also, as titanium hydride is very stable, it makes the study of the hydride form much easier. Therefore, it is a good system to study to get fundamental knowledge on the mechanism of hydrogenation on cold rolled alloys. Recently, Wen et al. have investigated the microstructural evolution induced by hydrogen in the commercial alloy Ti50A $(98.9 \% \mathrm{Ti}) .{ }^{17)}$ The originality of this work was that the titanium plates were first partially hydrogenated by electrolytic method up to hydrogen level of $138 \mathrm{ppm}$. This led to precipitation of $\delta$-TiHx and $\varepsilon$-TiH2 titanium hydrides that precipitated in the grain boundaries as well as within the $\alpha$-Ti matrix. The samples, of $1 \mathrm{~mm}$ thickness, were then cold rolled at room temperature with a thickness reduction of $5 \%$ per rolling pass until a total reduction of $10 \%$ to $50 \%$ was reached. Cold rolling produced an important reduction of Ti grain size, going from $12 \pm 0.8 \mu \mathrm{m}$ in as hydride state to $1.1 \pm 0.1 \mu \mathrm{m}$ after cold rolling. In the $10 \%$ reduction cold rolled samples, it was found that hydrogen facilitated the formation of tension twins $\{10-12\}\langle-1011\rangle$. Also, the formation of geometrically necessary dislocations was promoted in the presence of hydrogen. ${ }^{17)}$

\subsection{TiFe alloy}

Iron-titanium alloy (TiFe) is a well-known metal hydride that is attractive for commercial applications because of its low cost and temperature of operation near room temperature under mild hydrogen pressure. ${ }^{18,19)}$ Only a few investigations have been made on cold rolling of TiFe alloy. Edalati et al. performed groove rolling by encapsulating TiFe alloy inside stainless steel and rolling 4 times to achieve a reduction of the cross section from $5.8 \times 5.8 \mathrm{~mm}^{2}$ to $\sim 4.4 \times 4.4 \mathrm{~mm}^{2}{ }^{20}$ ) They found that the sample processed by groove rolling absorbed $0.3,1.0,1.4$ and $1.7 \mathrm{wt} . \%$ of hydrogen in the first, second, third and fourth hydrogenation cycles. Also, air exposure did not deactivate the sample. Lv and Huot studied the multiphase system TiFe $+\mathrm{X}$ wt. $\% \mathrm{ZrMn}_{2}(\mathrm{X}=2,4,8$, 12). ${ }^{21)}$ They found that, for this multiphase system, cold rolling has a minimal impact on the hydrogenation kinetics except for the compound $\mathrm{TiFe}+4 \mathrm{wt} . \% \mathrm{ZrMn}_{2}$ for which incubation time was eliminated by cold rolling. Vega et al. performed cold rolling of TiFe under an inert atmosphere. ${ }^{22)}$ The hydrogen absorption rate of cold rolled samples was high. Increasing the number of rolling passes produced an improvement in the hydrogen absorption rate. This was attributed to the increase of the surface area. They noted that cold rolling under an inert atmosphere is an alternative route to produce TiFe alloy. In a recent paper, Manna et al. found that cold rolling of air exposed $\mathrm{TiFe}+4 \mathrm{wt} . \% \mathrm{Zr}$ made the alloy reactive again toward hydrogen exposure. ${ }^{23)}$ However, the same beneficial effect was not seen for pure TiFe. The reason is probably due to the presence of a secondary Zr-rich phase in the TiFe +4 wt. $\% \mathrm{Zr}$ alloy. This secondary phase acts as a gateway for hydrogen and probably do not oxidize as easily as TiFe itself.

\section{6 $\quad \mathrm{AB}_{5}$ system}

The $\mathrm{AB}_{5}$ alloys where $\mathrm{A}$ is a hydrogen absorbing element and $\mathrm{B}$ a non-hydride forming element are extensively studied. They could store hydrogen at room temperature, but their hydrogen storage capacity is too low for many applications. One of the problems presented by this class of hydride is their slow first hydrogenation. ${ }^{24,25)}$ It has been reported that cold rolling is efficient to enhance the first hydrogenation of $\mathrm{LaNi}_{5}$ and $\mathrm{CaNi}_{5}{ }^{26,27)}$ For $\mathrm{CaNi}_{5}$ it was found that, even by performing the cold rolling in air, the incubation time for the first hydrogenation was reduced. This was attributed to the reduction of particle size and also decreases of crystallite size. However, as the rolling was performed in air, hydrogen capacity after cycling increased with the number of rolling passes.

\section{7 $\quad \mathbf{A B}_{2}$ system}

Metal hydrides of general composition AB2 are Laves phase alloys that usually have easy first hydrogenation, rapid kinetics and acceptable hydrogen storage capacity. They could also be used as battery materials. ${ }^{28)}$ However, when exposed to the air for a long period of time the alloy become totally inert to hydrogen. Recently, Khajavi et al. studied the effect of cold rolling and ball milling on air exposed Ti0.5Zr0.5Mn1 $-\mathrm{xFexCr} 1$ where $\mathrm{x}=0,0.2$ and $0.4 .{ }^{29)}$ They found that ball milling made the hydrogenation possible but with an important loss of capacity. Cold rolling was a more efficient way to reactivate the air-exposed alloy. After just one rolling pass in air, the air exposed alloy rapidly absorbed hydrogen without loss of capacity. However, more rolling 
passes bring an important reduction of hydrogen capacity. The explanation of such behaviour is still unclear and further tests are needed.

\section{8 $\quad \mathrm{Mg}_{2} \mathrm{Ni}$ alloy}

Effect of cold rolling on $\mathrm{Mg}_{2} \mathrm{Ni}$ has been sparsely investigated. In an early investigation, Ben Ameur and Yavari have shown that $\mathrm{Mg}-\mathrm{Ni}$ multilayers could be amorphized by repetitive rolling even if the heat of mixing is slightly negative. ${ }^{30,31)}$ Later, Ueda et al. investigated the $\mathrm{Mg}-\mathrm{Ni}-\mathrm{Mg} 2 \mathrm{Ni}$ laminates composites. ${ }^{32)}$ They found that by heat treatment, the $\mathrm{Mg}_{2} \mathrm{Ni}$ intermetallic could be formed by interdiffusion of the $\mathrm{Mg}$ and $\mathrm{Ni}$ thin layers formed by cold rolling. This was proof by the full hydrogenation of the sample having a ratio $\mathrm{Mg} / \mathrm{Ni}=2$. They showed that a combination of repetitive rolling and heat treatment could lead to the formation of the intermetallic $\mathrm{Mg}_{2} \mathrm{Ni}$. Pedneault et al. investigated the electrochemical properties of cold rolling Mg-Ni lamellar structures. ${ }^{33,34)}$ They confirmed that cold rolling followed by mild heat treatment produced the intermetallic $\mathrm{Mg}_{2} \mathrm{Ni}$ and nickel without formation of the $\mathrm{MgNi}_{2}$ alloy. The $\mathrm{Mg}_{2} \mathrm{Ni}$ formed by cold rolling had similar electrochemical hydrogen storage properties to that of ball milled $\mathrm{Mg}_{2} \mathrm{Ni}$ powder.

Similar to $\mathrm{AB}_{5}$ and magnesium alloys, the first hydrogenation of $\mathrm{Mg}_{2} \mathrm{Ni}$ alloy may be difficult to perform. We thus investigated the effect of cold rolling on the first hydrogenation of this alloy. The starting alloy was provided by Hydro-Quebec Research Center. Figure 2 shows the morphology of the starting powder. It is seen that the powder is mainly made of many irregular shaped particles with edges dimensions of a few hundred microns. There are also small particles of less than a few tenths of microns.

The purity of the as-received powder was verified using the X-ray powder diffraction pattern shown in Fig. 3.

A Rietveld refinement of the pattern shown in Fig. 3 gave the abundances of the $\mathrm{Mg}_{2} \mathrm{Ni}, \mathrm{Mg}$ and $\mathrm{MgNi}_{2}$ phases to be respectively $93 \mathrm{wt} . \%, 1 \mathrm{wt} . \%$ and $6 \mathrm{wt} . \%$. The presence of $\mathrm{Mg}$ and $\mathrm{MgNi}_{2}$ phases is easily understandable by inspecting the $\mathrm{Mg}-\mathrm{Ni}$ phase diagram.

Cold rolling was performed following the description given in the experimental section. Figure 4 shows the diffraction patterns of as-received and cold rolled samples.

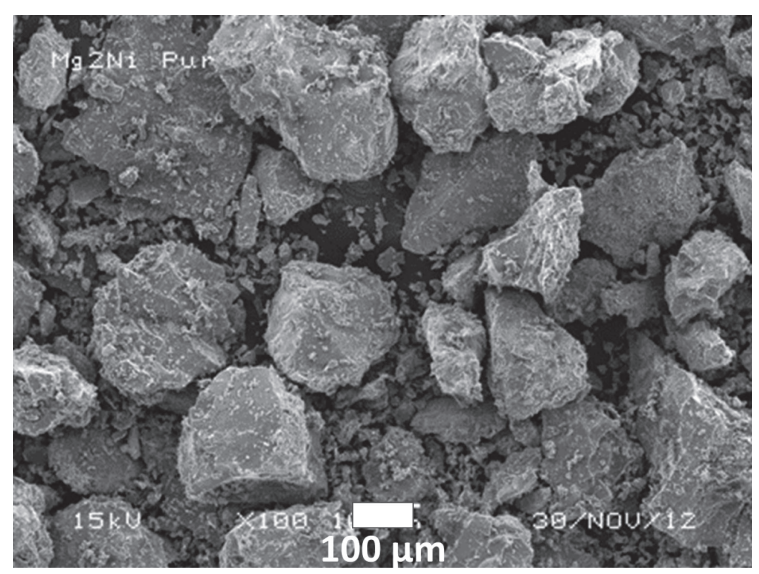

Fig. 2 Scanning electron micrograph of as-received $\mathrm{Mg}_{2} \mathrm{Ni}$ alloy.

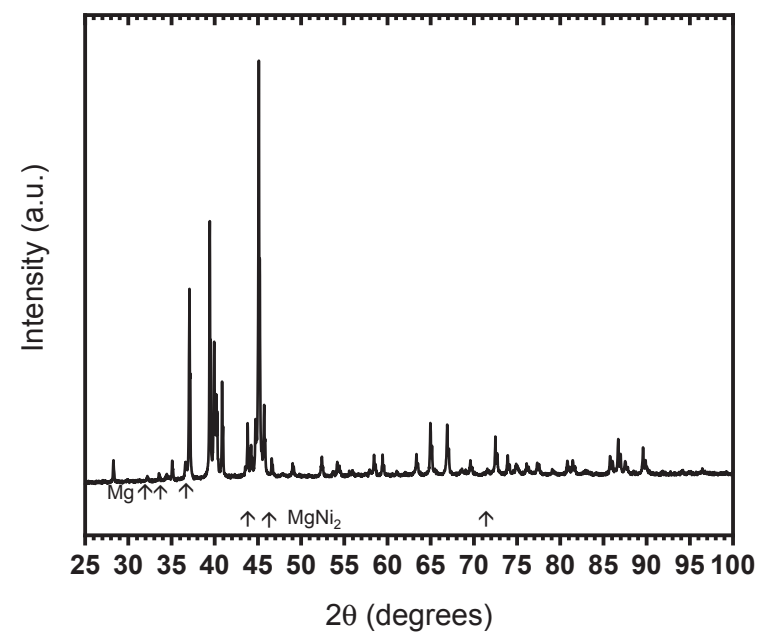

Fig. 3 X-ray powder diffraction of as-received $\mathrm{Mg}_{2} \mathrm{Ni}$ alloy. The main peaks indexed to $\mathrm{Mg}$ and $\mathrm{MgNi}_{2}$ phases are indicated by arrows. All other peaks belong to the $\mathrm{Mg}_{2} \mathrm{Ni}$ phase.

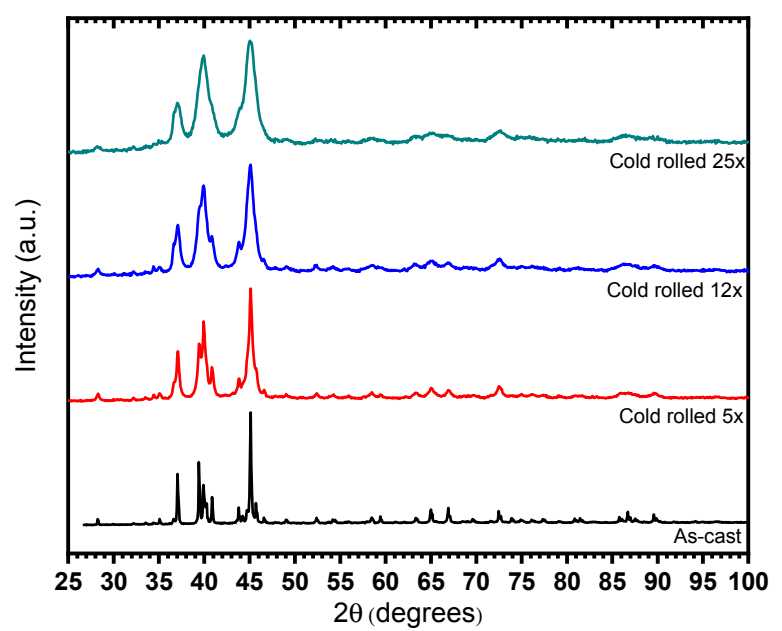

Fig. 4 X-ray powder diffraction of $\mathrm{Mg}_{2} \mathrm{Ni}$ alloy in the as-received and after cold rolling states.

It is clear from Fig. 3 that cold rolling had for effect of reducing the crystallite size thus leading to an increase in peak broadness. Rietveld refinement was performed on all these patterns. It was found that the abundances of $\mathrm{Mg}_{2} \mathrm{Ni}$, $\mathrm{Mg}$ and $\mathrm{MgNi}_{2}$ phases did not change with the number of rolling passes. However, the crystallite size and microstrain of the $\mathrm{Mg}_{2} \mathrm{Ni}$ phase drastically changed as shown in Table 1 . We see that most of the crystallite size reduction was due to

Table 1 Crystallite size and microstrains of $\mathrm{Mg}_{2} \mathrm{Ni}$ phase as determined by Rietveld refinement for as-received and cold rolled samples. The number in parentheses is the uncertainty on the last significant digit.

\begin{tabular}{ccc}
\hline $\begin{array}{c}\text { Number of } \\
\text { rolling passes }\end{array}$ & Crystallite size & Microstrain \\
\hline $0($ as - recived $)$ & $82(2)$ & $\%$ \\
5 & $14.6(1)$ & -- \\
12 & $10.8(1)$ & $0.22(4)$ \\
25 & $7.9(1)$ & $0.35(1)$ \\
\hline
\end{tabular}




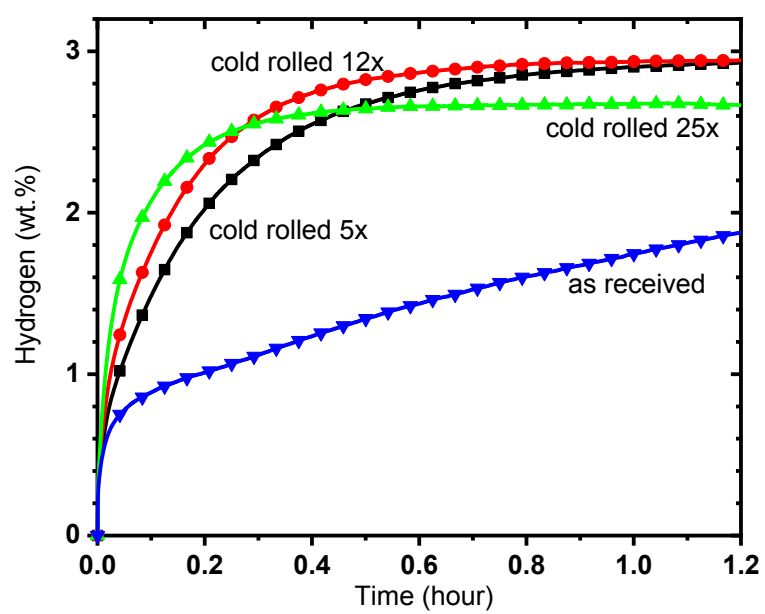

Fig. 5 First hydrogenation kinetics, at $350^{\circ} \mathrm{C}$ under $2000 \mathrm{kPa}$ of hydrogen, of $\mathrm{Mg}_{2} \mathrm{Ni}$ alloy in the as-received state and after cold rolling.

the first five rolling passes. Increasing the rolling pass number slightly reduced the crystallite size but mainly introduced microstrain.

The first hydrogenation kinetics of as-received and cold rolled samples are shown in Fig. 5. It is clear that cold rolling has a beneficial effect on the first hydrogenation but, as for crystallite size, most of the improvement was due to the first five rolling passes. It could also be seen that more rolling passes improved the kinetics but also led to a slight decrease in hydrogen capacity. This capacity loss is most likely due to the formation of oxides as the cold rolling was performed in air. Such phenomenon was seen in the case of cold rolling $\mathrm{MgH}_{2}$ in air. ${ }^{35)}$ The presence of oxide is difficult to see in the diffraction pattern because of the relatively small amount of that phase and also because the Bragg peaks are so broad (small crystallite size) that they merge into the background.

After the first hydrogenation, the samples were desorbed at $350^{\circ} \mathrm{C}$ and a second absorption under the same conditions as the first absorption. The absorption kinetic curves of the second cycle are shown in Fig. 6. Here, we could see that all curves have basically the same except for the sample cold rolled 25 times which again has a slightly lower capacity. This is a proof that the modifications made by cold rolling only influence the first hydrogenation and have basically no impact on the intrinsic kinetics of $\mathrm{Mg}_{2} \mathrm{Ni}$ phase.

The X-ray powder diffraction patterns of the samples after two absorption/desorption cycles are presented in Fig. 7. All patterns are very similar. Rietveld refinement was performed on all these patterns and the crystallite size and microstrain extracted from these refinements are given in Table 2 .

Comparison of Table 1 and Table 2 shows that, for the as-received sample the crystallite size decreased while for the cold rolled samples the crystallite size increased. Moreover, the two samples that did not show any microstrain before the first hydrogenation had a small amount of microstrain after two cycles while the samples that presented microstrain before hydrogenation did not have any microstrain after two hydrogenation/dehydrogenation cycles.

It seems that there is a 'natural' crystallite size for the $\mathrm{Mg}_{2} \mathrm{Ni}$ phase after hydrogenation. This may explain why the first hydrogenation of cold rolled samples is easier because

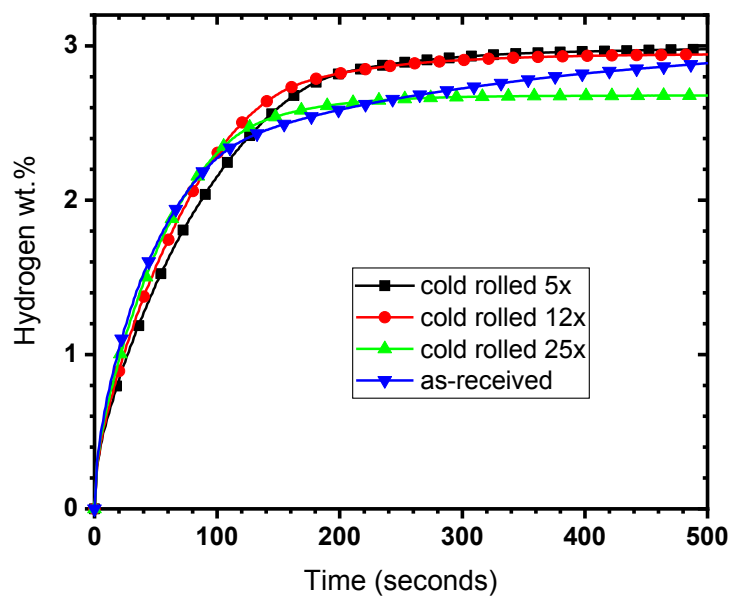

Fig. 6 Second hydrogenation kinetics, at $350^{\circ} \mathrm{C}$ under $2000 \mathrm{kPa}$ of hydrogen, of $\mathrm{Mg}_{2} \mathrm{Ni}$ alloy in the as-received state and after cold rolling.

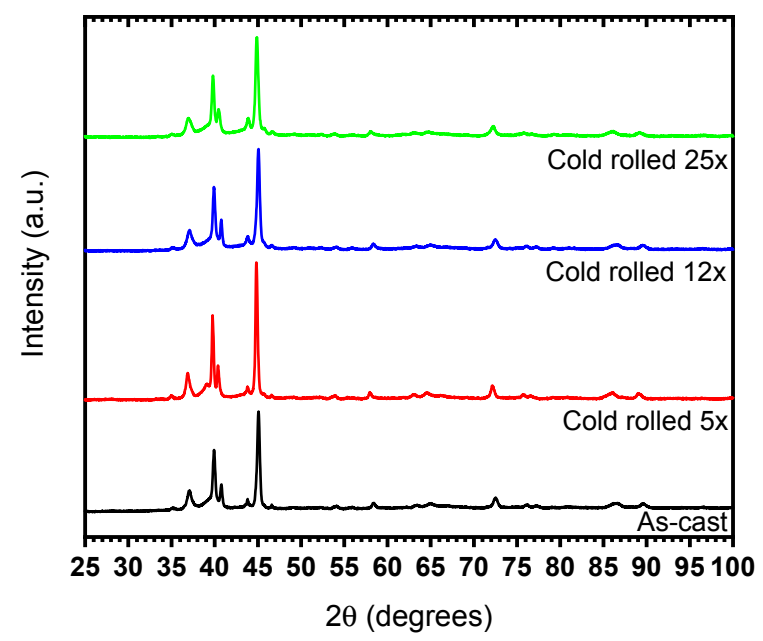

Fig. 7 X-ray powder diffraction after two hydrogenation/dehydrogenation cycles of as-received and after cold rolling $\mathrm{Mg}_{2} \mathrm{Ni}$ alloy.

Table 2 Crystallite size and microstrain as determined by Rietveld refinement for as-received and cold rolled samples after two hydrogenation/dehydrogenation cycles. The number in parentheses is the uncertainty on the last significant digit.

\begin{tabular}{ccc}
\hline $\begin{array}{c}\text { Number of } \\
\text { rol1ing passes }\end{array}$ & Crystal1ite size & Microstrain \\
\hline $0($ as - recived $)$ & $23.5(6)$ & $0.06(1)$ \\
5 & $28.7(6)$ & $0.03(1)$ \\
12 & $18.6(4)$ & -- \\
25 & $18.1(2)$ & -- \\
\hline
\end{tabular}

the crystallite size is much closer to this optimal size than the as-received sample. We fully understand that the behaviour of the crystallite size and microstrain may seem erratic. But we also feel that, for a better comprehension of this phenomenon more systematic and detailed measurements are needed. For example, performing more cold rolling and using X-ray diffraction coupled with TEM could bring a new point of view.

However, presence of defects which act as nucleation points for the hydride phase most probably play a role in 
the fast first hydrogenation kinetics of the cold rolled samples. ${ }^{36,37)}$

\section{Conclusion}

The effect of cold rolling on various metal hydride systems have been shown. Cold rolling usually enhances hydrogenation kinetics and improve the first hydrogenation. It also could change the microstructure by inducing texture. One of the interesting effects of cold rolling is its ability to regenerate air exposed hydrides. As the number of investigations increases, new effects of cold rolling on metal hydrides are found. However, in our opinion, the research is still mainly phenomenological. There is a lack of fundamental understanding on the exact action mechanism of cold rolling that enable all of these improvements to occur. This is a possible direction for future research.

\section{REFERENCES}

1) R.Z. Valiev, R.K. Islamgaliev and I.V. Alexandrov: Prog. Mater. Sci. 45 (2000) 103-189.

2) J. Huot: Enhancing Hydrogen Storage Properties of Metal Hydrides, (Springer, Berlin, 2016).

3) BRUKER_AXS, (Karlsruhe, Germany, 2014).

4) R.W. Cheary, A.A. Coelho and J.P. Cline: J. Res. Natl. Inst. Stand. Technol. 109 (2004) 1-25.

5) M.S. El-Eskandarany, M. Banyan and F. Al-Ajmi: RSC Advances 8 (2018) 32003-32008

6) A. Grill, J. Horky, A. Panigrahai, G. Krexner and M. Zehetbauer: Int. J. Hydrogen Energ. 40 (2015) 17144-17152.

7) J.J. Márquez, J. Soyama, R. de Araujo Silva, D.R. Leiva, R. Floriano, T.T. Ishikawa, C.S. Kiminami and W.J. Botta: Int. J. Hydrogen Energ. 42 (2017) 2201-2208.

8) J. Soyama, R. Floriano, D.R. Leiva, Y. Guo, A.M. Jorge Junior, E. Pereira da Silva, H.C. Pinto, C. Bolfarini, C.S. Kiminami and W.J. Botta: Int. J. Hydrogen Energ. 41 (2016) 11284-11292.

9) R. Floriano, D.R. Leiva, G.C. Melo, T.T. Ishikawa, J. Huot, M Kaufman, S.J.A. Figueroa, L.A. Mendoza-Zélis, L.C. Damonte and W.J. Botta: Int. J. Hydrogen Energ. 42 (2017) 29394-29405.

10) J.Y. Jung, J.O. Fadonougbo, J.-Y. Suh, Y.-S. Lee, J.-Y. Huh and Y.W. Cho: Int. J. Hydrogen Energ. 43 (2018) 16758-16765.

11) G.F. de Lima Andreani, M.R.M. Triques, C.S. Kiminami, W.J. Botta, V.
Roche and A.M. Jorge: Int. J. Hydrogen Energ. 41 (2016) 2309223098 .

12) F.J. Antiqueira, D.R. Leiva, T.T. Ishikawa, A.M. Jorge Junior and W.J. Botta: Mater. Res. 20 (2017) 61-70.

13) Q. Li, Q. Lin, K.-C. Chou, L.-J. Jiang and F. Zhan: J. Mater. Res. 19 (2004) 2871-2876

14) D. Liu, X. Liu, Y. Zhu and L. Li: J. Alloys Compd. 458 (2008) 394397.

15) J.J. Márquez, D.R. Leiva, R. Floriano, J. Soyama, W.B. Silva, T.T. Ishikawa, C.S. Kiminami and W.J. Botta: Int. J. Hydrogen Energ. 43 (2018) 13348-13355.

16) Z.Z. Fang, J.D. Paramore, P. Sun, K.S.R. Chandran, Y. Zhang, Y. Xia, F. Cao, M. Koopman and M. Free: Int. Mater. Rev. 63 (2018) 407-459.

17) J. Wen, N. Allain and E. Fleury: Mater. Charact. 121 (2016) 139-148.

18) J.J. Reilly and R.H. Wiswall: Inorg. Chem. 13 (1974) 218-222.

19) I.P. Jain, B. Devi and A. Williamson: Int. J. Hydrogen Energ. 26 (2001) 1183-1187.

20) K. Edalati, J. Matsuda, A. Yanagida, E. Akiba and Z. Horita: Int. J. Hydrogen Energ. 39 (2014) 15589-15594.

21) P. Lv and J. Huot: Energy 138 (2017) 375-382.

22) L.E.R. Vega, D.R. Leiva, R.M. Leal Neto, W.B. Silva, R.A. Silva, T.T. Ishikawa, C.S. Kiminami and W.J. Botta: Int. J. Hydrogen Energ. 43 (2018) 2913-2918

23) J. Manna, B. Tougas and J. Huot: Int. J. Hydrogen Energ. 43 (2018) 20795-20800.

24) S. Corre, M. Bououdina, N. Kuriyama, D. Fruchart and G. Adachi: J. Alloys Compd. 292 (1999) 166-173.

25) T. Kastrissios, E. Kisi and S. Myhra: J. Mater. Sci. 30 (1995) 4973.

26) J. Huot and M. Tousignant: J. Mater. Sci. 52 (2017) 11911-11918.

27) M. Tousignant and J. Huot: J. Alloys Compd. 595 (2014) 22-27.

28) K.-H. Young, S. Chang and X. Lin: Batteries 3 (2017) 27.

29) S. Khajavi, M. Rajabi and J. Huot: J. Alloys Compd. 775 (2019) 912920.

30) T.B. Ameur and A.R. Yavari: Collq. Phys. C 4 (1990) 219.

31) T.B. Ameur, A.R. Yavari and J.M. Barandiaran: Mater. Sci. Eng. A 134 (1991) 1402-1405.

32) T.T. Ueda, M. Tsukahara, Y. Kamiya and S. Kikuchi: J. Alloys Compd. 386 (2005) 253-257.

33) S. Pedneault, J. Huot and L. Roué: J. Power Sources 185 (2008) 566569.

34) S. Pedneault, L. Roué and J. Huot: Mater. Sci. Forum 570 (2008) 3338.

35) J. Lang and J. Huot: J. Alloys Compd. 509 (2011) L18-L22.

36) R. Floriano, D.R. Leiva, J.A. Carvalho, T.T. Ishikawa and W.J. Botta: Int. J. Hydrogen Energ. 39 (2014) 4959-4965.

37) D.R. Leiva, H.C.A. Costa, J. Huot, T.S. Pinheiro, A.M. Jorge, T.T. Ishikawa and W.J. Botta: Mater. Res. 15 (2012) 813-817. 